\title{
Artigos
}

\section{Os empreendedores políticos da economia solidária no Brasil: as ideias de Singer, Gaiger e Arruda}

\author{
Lorena Madruga Monteiro ${ }^{1}$
}

Sandra de Lourdes Gonçalves ${ }^{2}$

\section{Resumo}

Este trabalho tem como finalidade contribuir para a reflexão do papel desempenhado pelos empreendedores de políticas públicas no surgimento de política de apoio à Economia Solidária (ES). A Economia Solidária foi incorporada como Política Pública em 2003, através do SENAES/MTE. A agenda política sobre a ES foi definida pela participação de três pesquisadores que atuaram como empreendedores políticos: Paul Singer, Luiz Gaiger e Marcos Arruda. Esses pesquisadores exerceram influência na alternativa implementada, atuando como empreendedores políticos. Diante desse contexto, este artigo analisa as ideias desses três pesquisadores através de revisão sistemática de seus conceitos contidos em suas produções científicas. Considera-se que essas ideias fundamentaram a coalizão de defesa da política pública de Economia Solidária. Conclui-se que os três empreendedores políticos contribuíram cada um com perspectivas distintas. A partir da análise das suas ideias, considera-se que a Economia Solidária tem por vocação combinar uma dimensão comunitária (mais tradicional) com uma dimensão pública (mais moderna) na sua ação. Desta forma, existem pontos em comum entre as ideias desses autores, englobando não apenas aspectos mercantis, mas também os sociais e políticos, que se incorporaram na Política Nacional de Economia Solidária.

\section{Palavras-chave}

Economia Solidária. Empreendedor político. Coalizões de defesa.

\footnotetext{
${ }^{1}$ Doutora em Ciência Política pela Universidade Federal do Rio Grande do Sul (UFRGS), professora do Programa de Pós-Graduação em Sociedade, Tecnologias e Políticas Públicas do Centro Universitário Tiradentes (UNIT/AL) e pesquisadora do Instituto de Tecnologia e Pesquisa (ITP). E-mail: lorena.madruga@gmail.com.

2 Doutoranda no Programa de Pós-Graduação em Sociedade, Tecnologias e Políticas Públicas do Centro Universitário Tiradentes (UNIT/AL). E-mail: sandra.goncalves.doutorado@gmail.com.
} 


\begin{abstract}
This work aims to contribute to the reflection of the roles played by public policy entrepreneurs in the emergence of support polities regarding the Solidarity Economy (SE). The Solidarity Economy was incorporated as a Public Policy in 2003 through SENAES/MTE. The political agenda regarding the SE was defined by the participation of three researchers who acted as political entrepreneurs: Paul Singer, Luiz Gaiger and Marcos Arruda. These researchers exerted their influence on the implemented alternative, acting as political entrepreneurs. With this context, this article analyzes the ideas of these three researchers through the systematic review of their concepts comprised in their scientific works. It is considered that these ideas were the foundation of the Solidarity Economy public policy defense coalition. We concluded that each of the three political entrepreneurs contributed with distinct perspectives. From the analysis of these political entrepreneurs' ideas, it is considered that the Solidarity Economy has the vocation to combine a community dimension (more traditional) with a public dimension (more modern) in its action. Thus there are common parts among the ideas of these authors, encompassing not only mercantile aspects, but all the social and political aspects that are incorporated in the Solidarity Economy National Policy.
\end{abstract}

\title{
Keywords
}

Solidarity Economy. Political entrepreneur. Defense coalitions.

\section{Introdução}

Este trabalho tem como finalidade contribuir para a reflexão do papel desempenhado pelos empreendedores de políticas públicas no surgimento de política de apoio à Economia Solidária (ES) no Brasil. A reflexão política sobre a inclusão da perspectiva da Economia Solidária como política de geração de renda, trabalho e de combate à pobreza remete aos anos 1980, que, segundo Locks (2014), é o período em que os atores reivindicavam direitos diante da diversidade de questões negligenciadas pelo governo brasileiro e que necessitavam de resolução por meio de políticas públicas, em especial de soluções diante do crescente desemprego e da precarização do trabalho.

Por esse viés, o Partido dos Trabalhadores apareceu com maior possibilidade de oferecer alternativas políticas a esse contexto, colocando como uma das prioridades em seu programa de governo a criação de empregos, a redução das desigualdades sociais e a ampliação de programas sociais no país. Locks (2014) aponta como marco da inclusão da economia solidária no debate político a criação de grupos coletivos e associações pelo MST, no período de 1980 a 1989, a exemplo do Sistema Cooperativista dos Assentados e, depois, em 1992, da Confederação das 
Cooperativas de Reforma Agrária no Brasil (Concrab), com o objetivo de construir um cooperativismo alternativo ao modelo capitalista vigente.

Os primórdios de construção da ES no Brasil são marcados pela forte presença de setores progressistas da Igreja Católica, principalmente a Cáritas e a Comissão Pastoral da Terra (CPT), apoiando a luta pela reforma agrária e a organização de cooperativas rurais. Destaca-se, nesse sentido, a fundação, com a participação dos setores da Igreja Católica, da Associação Nacional dos Trabalhadores em Empresas de Autogestão e Participação Acionária (Anteag), em 1994.

A formulação da Política Pública de Economia Solidária ocorreu entre os anos de 1997-2002 a partir das discussões do Primeiro Encontro Latino-Americano de Cultura e Socioeconomia Solidária, realizado em Porto Alegre, 1998, da criação da Rede Socioeconômica de Economia Solidária (RBSES), em 2002, do Primeiro Fórum Social Mundial e do Fórum Brasileiro de Economia Solidária (FBES), em 2001. Entretanto, a Economia Solidária foi incorporada como Política Pública apenas em 2003, após a eleição do presidente Luís Inácio Lula da Silva, do Partido dos Trabalhadores. Criou-se, nesse ano, a Secretaria Nacional de Economia Solidária (SENAES), vinculada ao Ministério do Trabalho e Emprego (MTE). A criação da SENAES contou com o panorama geral do movimento de Economia Solidária no Brasil, que, segundo Borges e Souza (2015), é marcado pela defesa de atividades econômicas pautadas pelo respeito ao próximo na forma de produção, de distribuição, pelo preço justo e pelo respeito ao meio ambiente.

A Política Pública de Economia Solidária contou com especialistas que, segundo Capella (2016), pertencentes ou não aos quadros governamentais, compartilhavam ideias sobre essa política e interagiam em comunidades específicas para a implementação da política. A participação de três pesquisadores - Paul Singer, Luiz Gaiger e Marcos Arruda - como empreendedores da política de economia solidária definiram a agenda política sobre o assunto. Considera-se, em consonância com a literatura especializada, que a participação de empreendedores políticos na formulação de uma coalizão de defesa de determinada política amplia as chances de aceitação de novas propostas e de implementação da política pública. Esses atores, como empreendedores de políticas públicas, levam as ideias acerca da política além dos limites de suas comunidades específicas para o público em geral (CAPELLA, 2016). Conforme Capella (2016, p. 488) “os empreendedores são indivíduos (eventualmente pequenos grupos de pessoas) cuja principal característica consiste na defesa de uma ideia e na percepção de momentos oportunos para conectar ideias a respeito de problemas e soluções, produzindo mudanças em políticas públicas". Portanto, os empreendedores políticos são considerados essenciais em dois aspectos: na defesa e difusão de ideias relativas a 
uma política e nos processos de mudanças nas políticas públicas. Conforme Capella (2016), os empreendedores políticos:

[...] são indivíduos que têm crédito frente a uma audiência, ou seja, detêm legitimidade possivelmente devido a fatores como a especialidade no assunto em questão (expertise), a habilidade na comunicação, ou sua posição formal no processo decisório. A segunda característica do empreendedor está relacionada às conexões políticas e habilidades de negociação desses indivíduos. Por fim, a persistência é apontada pelo autor como a terceira característica vital para a atividade do empreendedor, implicando a disponibilidade de investimento de grandes quantidades de recursos pessoais. (CAPELLA, 2016, p. 489).

Portanto, essas características apontam os três fluxos (problemas, soluções e dinâmica política) que podem convergir, criando uma possibilidade concreta de mudança na agenda governamental. Desta forma, a produção de políticas públicas, especialmente as dedicadas à formação da agenda (agenda-setting), têm destacado o papel central dos empreendedores de políticas (CAPELLA, 2016).

Diante desse contexto, este artigo analisa as ideias de três empreendedores políticos através de revisão das suas ideias contidas em suas produções científicas. Considera-se que essas ideias fundamentaram a coalizão de defesa da política pública de Economia Solidária o que a manteve na agenda governamental. Os três empreendedores políticos contribuíram cada um com perspectivas distintas. A análise das ideias desses empreendedores considera que a economia solidária tem por vocação combinar uma dimensão comunitária (mais tradicional) com uma dimensão pública (mais moderna) na sua ação.

$\mathrm{O}$ artigo divide-se em quatro tópicos, além da introdução. No primeiro apresentam-se as ideias de Paul Singer e seu papel como empreendedor político na institucionalização da economia solidária na política brasileira. No segundo tópico, analisou-se a trajetória das ideias de Luiz Gaiger e seu papel no desenvolvimento da ES como conhecimento científico. No terceiro tópico, destaca-se a perspectiva comunitária da ES no sentido atribuído por Marcos Arruda e a ênfase na participação popular no desenvolvimento da política ES. Na última parte, apresenta-se a análise das semelhanças entre os empreendedores políticos.

\section{Paul Singer e a institucionalização da política}

Segundo Souza (2018), Paul Singer compreendia a economia solidária a partir de princípios voltados para a democracia interna e a perenidade econômica. Esse 
empreendedor, aliado a uma rede global de discussão sobre associativismo comunitário e economia, organizada desde os anos 1990, usou a categoria economia solidária para nomear a proposta de política pública elaborada em 1996 para o programa partidário do Partido dos Trabalhadores (PT). Conforme Locks (2014), a indicação e posterior nomeação de Paul Singer como secretário de Economia Solidária no segundo ano do primeiro mandato de Lula da Silva (PT) foi por sugestão das redes de economia solidária que se fortaleceram no Fórum Social Mundial através de um grupo de trabalho específico. Um ano antes de sua nomeação, Paul Singer organizou, juntamente com André Ricardo de Souza, um livro de referência nesse campo de discussão. Trata-se da obra "A Economia Solidária no Brasil: a autogestão como resposta ao desemprego" lançada, em 2002, no seminário Trabalho e Economia Solidária: políticas públicas para o desenvolvimento, organizado pelo governo do Estado do Rio Grande do Sul na cidade de Porto Alegre (LOCKS, 2014).

Já nessa primeira iniciativa, Singer (2002) considerava a economia solidária uma forma de tornar as muitas cooperativas, associações, etc., conhecidas entre si e criar formas de troca solidária, de comércio solidário, com o objetivo, segundo ele, de construir um modo de produção alternativo ao modo de produção capitalista. Para Singer et al (2003), a importância da ES está no fato de o "trabalho e capital estarem fundidos porque todos os que trabalham são proprietários da empresa e não há proprietários que não trabalhem na empresa". Nesse sentido, a propriedade da empresa é dividida por igual entre os participantes do empreendimento e, assim, todos têm o mesmo poder de decisão sobre ela. Empresas solidárias são, em geral, administradas por sócios eleitos para a função e que atuam conforme as diretrizes aprovadas em assembleias gerais ou, quando a empresa é grande demais, em conselhos de delegados eleitos por todos os trabalhadores. Portanto, conforme Singer (2002), para eliminar o capitalismo, ou reduzir seus efeitos perversos, é preciso, em primeiro lugar, que os trabalhadores sejam capazes de praticar autogestão e que isso só se aprende praticando. No ponto de vista de Singer (2002), a solução é a associação solidária de várias pequenas ou microempresas, oferecendo a possibilidade de cooperação e intercâmbio, que aumentam suas probabilidades de êxito.

A trajetória de Paul Singer associada às ideias da economia solidária remete à década de 1990. Em 1998, Singer conduziu, no prédio da Faculdade de Filosofia, Letras e Ciências Humanas da USP, o grupo de estudos sobre autogestão, em que se produziu a proposta inicial da Incubadora Tecnológica de Cooperativas Populares da USP, a ITCP-USP (SOUZA, 2018). Inicialmente, Singer via a ES como uma solução para o desemprego, para a miséria. O contato com outros especialistas 
no tema modificou sua concepção inicial do papel da ES. Ao juntar-se a esse contato com outros especialistas em ES, sua participação constante em seminários e congressos proporcionou as condições para que exercesse assessoria a sindicatos e organizações, como a Central Única dos Trabalhadores (CUT), as organizações da Agência de Desenvolvimento Sustentável (ADS) e a Associação Nacional dos Trabalhadores em Empresas de Autogestão e Participação Acionária (Anteag). Essas instituições originaram-se a partir do Movimento Sindical. Participou e assessorou, ainda, o Partido dos Trabalhadores e a Incubadora Tecnológica de Cooperativas Populares, da USP, da qual foi um dos fundadores (LECHAT, 2004).

Em 1989 foi convidado pela prefeita de São Paulo, Luiza Erundina, para ser Secretário Municipal de Planejamento de São Paulo, cargo que desempenhou durante esse mandato (1989/93) e durante o qual elaborou um programa de combate ao desemprego. Singer considerou essa experiência como uma gestão interessante e uma experiência militante, conforme expressou em entrevista a Andrada e Esteves (2018):

Eu fiz uma proposta formal à campanha da Luiza Erundina, que foi novamente candidata a prefeita, mas acabou sendo derrotada. O candidato a vice-prefeito era o [Aloísio] Mercadante. Foi nesse momento que sugeri, em uma reunião da Comissão do Programa [de Governo], que o Mercadante dirigia e eu era membro, sugeri que a Economia Solidária poderia ser um bom item para o programa da Luiza Erundina. Foi discutido e foi aceito, ninguém foi contra [...] (ANDRADA; ESTEVES, 2018, p. 376).

Em 2003, Singer assumiu a Secretária Nacional da Economia Solidária, no Ministério do Trabalho e Emprego. Neste mesmo ano propôs uma moeda própria a ser usada entre cooperados brasileiros que poderia ser chamada de "sol" (de solidariedade), propondo a utilização no Brasil em feiras de trocas. Hoje a moeda social é encontrada em vários municípios que a utilizam como meio que viabiliza a prática da Economia Solidária e como uma ferramenta de democratização do crédito, permitindo a ampliação de investimentos locais.

Singer trata as formas autogestionárias de produção como elemento importante para a preparação de um novo modo de produção, que seria capaz de competir com o modo de produção capitalista. Segundo Singer, em entrevista a Oliveira (2008), um dos problemas enfrentados pelos cooperados é falta de cultura cooperativa, dificultando a formação dos empreendimentos solidários. Por outro lado, as cooperativas autogestionárias, quando bem-sucedidas, acabam por trazer novos problemas, sendo o maior deles o fato de perder seu ideal transformando-se em empresa capitalista. Singer, entende, portanto, que o que impulsiona o 
desenvolvimento da economia solidária não é mais somente o desemprego e a exclusão social, mas a democracia participativa, a expansão do conhecimento (SINGER, 2002).

Segundo Souza (2018), a publicação do livro Introdução à economia solidária, cuja orelha da obra foi escrita por Luiz Inácio Lula da Silva, antes de ser eleito pela primeira vez à Presidência da República, impulsionou uma visibilidade política ainda maior do GT brasileiro junto a fóruns estaduais e regionais de economia solidária. Souza (2018) destaca que André Singer, então porta-voz do presidente Lula, anunciou a oficialização da SENAES/MTE, que teria no comando seu pai (Paul Singer), juntamente com a formação do Fórum Brasileiro de Economia Solidária (FBES).

\section{Luiz Inácio Germany Gaiger e o desenvolvimento da Economia Solidária como conhecimento científico}

A trajetória de Gaiger é quase totalmente acadêmica. Diretor de Pesquisa da Unisinos e chefe de equipe de investigações, articula, em seu trabalho, muitas parcerias relacionadas à economia solidária no campo científico a partir da categoria "empreendimentos solidários" que, segundo Gaiger (2008), situa-se no "interstício da economia de mercado em contraposição à sua lógica mercantilista". Segundo Lechart (2004) um dos fatos importantes para a trajetória de Gaiger na economia solidária foi sua participação no Seminário Nacional de Economia Solidária da Unitrabalho como representante da região Sul. Conforme Locks (2014, p. 54):

[...] já em 2004, fruto de um projeto de pesquisa que se estendia desde os primeiros simpósios da rede Unitrabalho, foi publicado o livro organizado por Luiz Inácio Gaiger. Nesse, percebemos um primeiro esforço em tentar captar as diferenças e similitudes da economia solidária no território brasileiro a partir de uma perspectiva estritamente acadêmica realizada por diferentes grupos de pesquisa nacionais. Como podemos perceber, a Unitrabalho, além da publicação do livro, foi uma das principais responsáveis pelo estabelecimento dos primeiros contatos entre os diversos intelectuais brasileiros que já estavam pesquisando sobre temas relacionados à economia solidária.

A partir de 1997, Gaiger assumiu a coordenação nacional de um programa de pesquisa do Unitrabalho intitulado "Significado e tendências da Economia Solidária no Brasil". A partir de 2001, fez parte do GT de economia solidária, 
participando do Fórum de Economia Solidária como representante da Unitrabalho. Em 2003, integrou o corpo profissional da Maestria em Economia Social (MAES), cujo diretor é José Coraggio, e fez parte da Rede de Investigadores Latinoamericanos de Economia Solcial y solidaria (RILESS). Essa rede teve como objetivo construir um espaço de produção científica cooperativa e de reflexão coletiva sobre os desafios que colocam as práticas da nova economia. No Brasil, Gaiger integra a Associação Brasileira de Pesquisadores de Economia Solidária. (LECHAT, 2004).

Gaiger e Asseburg (2007) propõem que a ideia central de Economia Solidária reside na simbiose que se estabelece entre aspectos solidários e empreendedores dessas iniciativas, engendrando um círculo virtuoso que se vale das forças da associação e do trabalho cooperativo. Para ele, "mais correto é conceber a Economia Solidária como outra forma de produzir e de propiciar a circulação de bens e serviços, assegurando com isso a sobrevivência econômica e melhores condições de vida a seus participantes" (GAIGER, 2009, p. 93). Desta forma, o autor aponta que a Economia Solidária termina assumindo a defesa de melhorias nos serviços comuns e a promoção de garantias mínimas a pessoas desprotegidas. É importante esclarecer que Gaiger (2003) conclui que os empreendimentos solidários estão aptos a credenciarem-se como formas consistentes de vida econômica, sem forçar a reprimir por limites próprios ou por externalidades que os condenassem a um fenômeno sazonal, reativo às flutuações da economia de mercado e assim:

A economia solidária adquire relevância porque assinala o reaparecimento do associativismo entre os trabalhadores, um fenômeno com larga história e múltiplos desenlaces. Embora envolva categorias sociais diversas e comporte variadas formas de organização, de grupos informais e pequenas associações a cooperativas e empresas de pequeno e médio porte, o que particulariza suas experiências é o fato de eliminarem o mecanismo estrutural que separa e contrapõe os processos de produção, gestão, produção e apropriação. (GAIGER, 2008, p. 13).

Ainda segundo Gaiger (2009, p. 93), “a Economia Solidária não pode dispensar o Estado, pois este constitui um alicerce para a sustentação inicial e o desenvolvimento ulterior dos mais diversos setores econômicos". Para ele a viabilidade dos empreendimentos solidários requer princípios reguladores, no sentido de preservar uma efetiva democracia econômica. Os EES se posicionam, nesse sentido, como ator coletivo, que se dota de identidade, formula princípios e programas de ação e institui estruturas representativas "compelidas à tarefa adicional de criar canais de comunicação e negociação entre os atores políticos, tanto do Estado quanto da sociedade civil"' (GAIGER, 2009, p.94). 
Gaiger (2015, p. 45), em trabalho mais recente, propõe que o efeito promissor da Economia Solidária é a questão da "aptidão a estimular e compensar o protagonismo econômico e político de trabalhadores pobres, vulneráveis à exclusão social, através de sua organização econômica e de seu envolvimento na condução dos empreendimentos". Entende-se, assim, que fatores do processo democrático muito influenciam nessa postura, implantando uma cultura de participação nos membros desses empreendimentos.

A trajetória de Gaiger, portanto, em termos de produção de conhecimento em Economia Solidária, se dá a partir de sua participação no Seminário Nacional de Economia Solidária da Unitrabalho como representante da região Sul. A partir desse momento sua participação como coordenador nacional de pesquisa refletindo os significados e tendências da economia solidária no Brasil contribuiu para a visibilidade da ES em nível nacional e internacional. Em 2004, passou a integrar a Associação Brasileira de Pesquisadores em Economia Solidária.

\section{Marcos Arruda e a perspectiva comunitária da economia solidária}

Marcos Arruda, geólogo e economista de formação, apresenta em suas reflexões sobre ES grande preocupação filosófica. Arruda (2000) construiu seu conceito de Socioeconomia articulando-se como liderança ou como assessor político, sempre atento para ocupar novos espaços, em território nacional e internacional (LECHAT, 2004). Segundo Arruda (2000, p.61), a "proposta de cooperativismo popular é apresentada como um caminho promissor de auto-organização dos trabalhadores em nível local, nacional e internacional".

Lechat (2004) considera que Arruda tem uma postura mais normativa, muito menos investigativa, diferentemente de Gaiger e Singer, deixando de perguntar como as coisas se desenvolveram ou por que aconteceram, para afirmar como as coisas devem acontecer ou como devemos agir em relação à Economia Solidária.

Arruda, segundo Lechat (2004), participou, em 1998, da criação da Rede Gaúcha de Socioeconomia Solidária, em Porto Alegre, e do Fórum para o Desenvolvimento do Cooperativismo popular, realizado no Rio de Janeiro, a partir de 2001. Trabalhou com a Rede Brasileira de Socioeconomia Solidária (RBSES), com o PACS, e atuou no Programa Nacional de Trabalho e Socioeconomia Solidária da Fase e no RBSES. Realiza palestras em todo o país e presta assessoria a gestores públicos, sindicatos, ONGs e entidades religiosas.

Arruda discute as transformações provocadas pela globalização das relações produtivas e sociais, propondo um outro processo de organização da consciência humana, e afirma que existe uma outra realidade, uma economia centrada no ser 
humano situado no seu meio natural, e, portanto, subordinada à política da partilha e à ética da sustentabilidade da vida (ARRUDA, 2005). Empregou a categoria socioeconomia solidária para batizar os programas educativos na área de geração de trabalho e renda (LECHAT, 2004). Segundo Arruda (2000b, p.4), “o associativismo e o cooperativismo autogestionários, transformados em projeto estratégico, podem ser os meios mais adequados para a reestruturação da socioeconomia na nova era que se inicia".

Para Arruda (2005, p.36), a Economia Solidária promove a "produção autogestionária dos bens e dos serviços". Cada pessoa que trabalha nessa produção tem o direito de participar da posse e da gestão do empreendimento produtivo, e o que lhe dá esse direito não é a quantidade de cotas que possui, mas o fato de contribuir com seu trabalho para o produto coletivo. Portanto, Arruda (2000) acredita na conversão da Economia Solidária de fim em meio de gerar bem-estar a cada um e a todos os cidadãos. Porém, isso não significa a abolição total do mercado e nem o fortalecimento absoluto do Estado, mas uma participação ativa como sujeito de todos os mercados, o que implica a democratização do mercado e do Estado. Nesse sentido, o mercado deve ser recriado sob o controle da sociedade civil e de um Estado democratizado, subordinando os interesses privados às prioridades do desenvolvimento humano (LECHAT, 2004).

Portanto, na Economia Solidária deve-se conviver de diversas formas de propriedade e de gestão, como explica Arruda, porém, todas elas devem estar vinculadas à não exploração do trabalho humano, à garantia de acesso de todos aos bens públicos que pertencem ao domínio coletivo, e a relações harmônicas com o meio ambiente. Portanto, Arruda (2000, p.46) declara que a única forma racional de interdependência é a que se baseia em direitos e oportunidades iguais para todos, na cooperação em vez da competição, e no respeito pelos limites da natureza e pelos direitos das gerações futuras. Segundo Lechat (2004, p.190):

Arruda legitima sua fala no fato desta ter por viés suas práticas e trabalho local de desenvolvimento e educação integrais em diversos movimentos sociais brasileiros e internacionais, associadas à pesquisa sobre temas macroeconômicos e sociais. Arruda cria uma série de novos conceitos como o de empresa-comunidade humana, ecossociedade, ecoeconomia, entre outros, como a noodiversidade, a noohistória, para marcar, no primeiro caso, a novidade de suas propostas, no segundo sua empatia com as concepções filosóficas.

Quanto ao processo educativo, entende que é necessário um processo de formação usando a metodologia de Paulo Freire, com o intuito de elevar a 
consciência para a crescente autonomia do indivíduo e da coletividade, propondo uma mudança cultural, de valores e de comportamento. Arruda afirma que só a educação e o empoderamento permitem o autodesenvolvimento (ARRUDA, 2005). Nesse sentido, o desenvolvimento integral, pessoal, comunitário, social, é o objetivo da educação emancipadora, ligada ao processo educativo que deve ser concebido como um espaço de práxis social e produtiva dos participantes.

\section{Análise das semelhanças entre os empreendedores políticos da economia solidária}

Pode-se dizer que os três empreendedores contribuíram para construir o que hoje conhecemos como Economia Solidária, cada um a seu jeito. Para Lechat (2004), Arruda trabalha a Economia Solidária ou Socioeconomia Solidária como projeto de vida, uma proposta de justiça para o trabalhador; ao passo que Singer retoma a proposta do socialismo, um socialismo democrático, humanizado e autogestionário; e, por último, Gaiger, trata a Economia Solidária a partir da sua especialidade científica. Conforme Locks (2014, p. 55)

Enquanto Gaiger atuava especificamente no âmbito acadêmico, Singer, além de incidir sobre o cenário intelectual, parece se deslocar de maneira mais profunda na política nacional quando da inserção do PT no governo federal. No entanto, Arruda situa-se em um terreno intermediário a Singer e Gaiger, como acadêmico, militante político e ativista de organizações do terceiro setor

Arruda e Singer propuseram o diálogo com comunidades externas a partir da Economia ou Socioeconomia Solidária, divulgando em jornais de grande circulação, revistas de ONGS ou em palestras, ao passo que Gaiger impulsionou a divulgação científica. Lechat (2004, p.291) declara, em sua análise dos três empreendedores, que Singer parte de uma análise histórica, Arruda nos projeta no futuro e Gaiger fica no presente. Quanto ao campo conceitual, os três empreendedores conceituam Economia Solidária conforme o Quadro 1 a seguir: 


\begin{tabular}{|c|l|}
\hline \multicolumn{1}{|c|}{ Quadro 1 - Campo Conceitual da Economia Solidária } \\
\hline Autor & \multicolumn{1}{c|}{ Conceito } \\
\hline Paul Singer & $\begin{array}{l}\text { A economia solidária é hoje um conceito amplamente utilizado dos } \\
\text { dois lados do Atlântico, com acepções variadas, mas que giram todas } \\
\text { ao redor da ideia da solidariedade, em contraste com o individualismo } \\
\text { competitivo que caracteriza o comportamento econômico padrão nas } \\
\text { sociedades capitalistas. O conceito se refere a organizações de } \\
\text { produtores, consumidores, poupadores, etc., que se distinguem por } \\
\text { duas especificidades: (a) estimulam a solidariedade entre os membros } \\
\text { mediante a prática da autogestão e (b) praticam a solidariedade para } \\
\text { com a população trabalhadora em geral, com ênfase na ajuda aos mais } \\
\text { desfavorecidos (SINGER, 2003, p.116). }\end{array}$ \\
\hline Arruda & $\begin{array}{l}\text { Afirma que o termo Socioeconomia Solidária é equivalente ao de } \\
\text { Economia Solidária com a ressalva de dar ênfase ao sentido social. } \\
\text { “Economia solidária é uma forma simplificada de referência à } \\
\text { socioeconomia solidária" (ARRUDA, 2003, p.235). }\end{array}$ \\
\hline Luiz Gaiger & $\begin{array}{l}\text { Os empreendimentos de economia solidária, em função de suas } \\
\text { condições de gênese e de suas características intrínsecas, tendem a } \\
\text { adotar regimes de igualitarismo na distribuição dos seus resultados. } \\
\text { Sustentam que os membros de tais iniciativas estabelecem vínculos } \\
\text { mútuos, estendendo-os solidariamente a setores sociais expostos a } \\
\text { maiores necessidades. Nos limites do seu campo de ação, essas } \\
\text { organizações tenderiam a incidir sobre as divisões imperantes na } \\
\text { sociedade, quebrando elos de reprodução das desigualdades (GAIGER; } \\
\text { ASSEBURG, 2007). }\end{array}$ \\
\hline
\end{tabular}

Fonte: Elaborado pelas autoras (2019).

O tema Economia Solidária no primeiro Fórum Social Mundial foi o assunto central. Singer figurou como palestrante, entre outros intelectuais, e foi a primeira vez que estiveram junto com ele Gaiger e Arruda, com suas especificidades e divergências (LECHAT, 2004). Apesar de muito diferentes, podemos verificar que os três empreendedores apresentam semelhanças na promoção da ES na agenda pública. Capella (2016, p.488), a partir do modelo dos múltiplos fluxos de Kingdon, identifica as características essenciais dos empreendedores políticos:

Em primeiro lugar, são indivíduos que têm crédito frente a uma audiência, ou seja, detêm legitimidade possivelmente devido a fatores como a especialidade no assunto em questão (expertise), a habilidade na comunicação, ou sua posição formal no processo decisório. A segunda característica do empreendedor está relacionada às conexões políticas e habilidades de negociação desses indivíduos. Por fim, a persistência é apontada pelo autor como a terceira característica vital para a atividade do empreendedor, implicando a disponibilidade de investimento de grandes quantidades de recursos pessoais (KINGDON, 2003, p.181 apud CAPELLA, 2016, p. 488). 
Desta forma, esses empreendedores apresentaram as qualidades propostas por Kingdon, qualidades as quais foram úteis na promoção das ideias, propostas e concepções a respeito dos problemas, e, no momento em que surgiu a oportunidade de mudança no debate público, conseguiram impactar a agenda governamental. Locks (2014, p. 55) compartilha dessa percepção:

Embora em intensidades distintas, esses três intelectuais podem ser caracterizados como empreendedores políticos (KINGDON, 2003), pois escrevem cartas, artigos em jornais e revistas e possuem contatos com pessoas que podem definir a agenda. Investiram seus diferentes recursos para o reconhecimento público e divulgação da economia solidária como uma política pública viável e necessária no cenário nacional, evidenciando que uma das bases de sustentação e crescimento da economia solidária se deu a partir da atuação em diferentes frentes dos intelectuais brasileiros. Contudo, não formavam um grupo homogêneo, pois suas ideias sobre o que era e o que deveria ser a economia solidária eram divergentes.

Portanto, entende-se que, apesar das diferenças, os três empreendedores possuem semelhanças que proporcionaram uma forma diferenciada de entender as formas de divulgação utilizadas por cada um dos Empreendedores Políticos da economia solidária com o intuito de possibilitar a implantação da política.

\section{Considerações finais}

A Economia Solidária ainda hoje é uma proposta de uma nova sociedade onde haja a partilha social da riqueza, do poder e do saber, na qual os trabalhadores possam, por meio da autogestão, gerir seus empreendimentos coletivamente e ter um desenvolvimento sustentável. Para Gaiger e Singer, a ES é alternativa ao modo de produção capitalista. Para Singer, a economia solidária é outro modo de produção, cujos princípios básicos são a propriedade coletiva ou associada e o direito à liberdade individual.

O resultado natural é a solidariedade e a igualdade, cuja reprodução, no entanto, exige mecanismos estatais de redistribuição solidária de renda (SINGER, 2002). Gaiger (2000) concorda que a Economia Solidária seja considerada como novo modo de produção, alternativo ao modo de produção capitalista, mas seu argumento é que "o capitalismo reduz a uma parcela mínima aqueles que podem usufruir das benesses do desenvolvimento. Enquanto exatamente por se contraporem a isso, as cooperativas teriam a possibilidade e a tendência a generalizar esses benefícios". Portanto, a ES aparece como uma alternativa aos 
problemas de empregabilidade enfrentados pelo poder público e pelo setor privado (GAIGER, 2000, p.187).

Singer e Arruda destacam a importância da educação para a mudança através do ensino e do mundo mediante análises macroeconômicas e o engajamento político e partidário. Já Gaiger tornou-se especialista da Economia Solidária brasileira e realiza o mapeamento do campo com seus empreendimentos e entidades de apoio, apontando desafios e possibilidades. Um dado importante levantado por Lechat (2004), por meio da análise bibliométrica, é a diferença entre os empreendedores políticos analisados. Uma diferença é a questão das citações realizadas em suas produções. Arruda e Gaiger citam, ao mesmo tempo, Marx e Gramsci, Singer faz referência aos conceitos marxistas sem citar nominalmente os autores. Gaiger cita muitos autores, inclusive Singer e Arruda. Já Singer cita poucos autores, mas, em sua maioria, quando citados, são autores ingleses. Singer é o único autor citado sem exceção por todos os autores do tema. Gaiger é muito pouco citado, apesar de ter muitas publicações, sendo muito citado por ele mesmo. $\mathrm{O}$ fato de Singer citar Gaiger, segundo Lechat (2004), denota a vontade desse intelectual de conciliar o campo.

Pode-se dizer, portanto, que Singer e Arruda são, segundo Lechat (2004), propagandistas da Economia Solidária, enquanto Gaiger não se encaixa nesse perfil, sendo um pesquisador acadêmico; suas análises dizem respeito aos empreendimentos econômicos solidários, às respectivas entidades de apoio e à ação do Estado. Assim, o que pode ser visto neste estudo é que os três empreendedores, além de terem em si as características que os definem como tais, atuaram, como proposto por Capella, na divulgação da Economia Solidária, com o intuito de possibilitar a implantação da política pública, sendo considerados essenciais na defesa e difusão de ideias relativas à política de Economia Solidária.

Entende-se, dessa forma, segundo Lechat (2004), que entidades de apoio e fomento, redes de relações sociais se estabelecem entre empreendedores, que sentidos podem ser repassados, compartilhados, questionados e reformulados. Por fim, entende-se que a Economia Solidária necessita de uma base de apoio, representada por ativistas, mediadores, educadores, especialistas, idealizadores, pesquisadores e analistas, para intervir no debate público e influenciar a agenda governamental, como foi o caso, em relação a esses atores, quanto à implantação da Política Pública de Economia Solidária, implementada em 2003, através do SENAES/MTE. 


\section{Referências}

ANDRADA C.; ESTEVES, E.

(2018). Paul Singer: uma vida de luta e de trabalho pelo socialismo e pela participação democrática. Estudos avançados. vol.32 n.93. São Paulo. Disponivel em:

http://www.scielo.br/scielo.php?script=sci_artt ext\&pid=S0103-40142018000200373

ARRUDA, $M$.

(2000a). Um novo humanismo para uma nova economia. In: KRAYCHETE, Gabriel et al. Economia dos setores populares: Entre a realidade e a utopia. Petrópolis: Editora vozes (UCSal, Capina e Cese) pp. 115-130.

(2000b). Globalização e sociedade civil: repensando o cooperativismo no contexto da cidadania ativa. Conferência sobre Globalização e Cidadania, organizado pelo Instituto de pesquisa da $0 \mathrm{NU}$ para o desenvolvimento social. In: ARRUDA, M; BOFF, Leonardo. Globalização: desafios socioeconômicos, éticos e educativos: uma visão a partir do Sul. Petrópolis: Vozes, 2000

(2002). Entrevista concedida. Rio de Janeiro, 24 abril.

(2005). Redes, educação e Economia Solidária: novas formas de pensar a Educação de Jovens e Adultos In: KRUPPA, S. M. P. Economia solidária e educação de jovens e adultos. Brasília: Inep, pp. 31-40.

BORGES, T; SOUZA, M.

(2015) 0s Atores da Economia Solidária: Um Estudo Sobre a Personalidade Ética. Revista do Centro Interdisciplinar de Desenvolvimento e Gestão Social - CIAGS \& Rede de Pesquisadores em Gestão Social - RGS. v.6, n.1, jan./jun. 2015. Acesso em: 24 abr. 2018. Disponível em: https://portalseer.ufba.br/index.php/cgs/articl e/view/31647/pdf_94

CAPELLA, A. C. N.

(2016). Um estudo sobre o conceito de empreendedor de políticas públicas: Ideias, Interesses e Mudanças. Cad. EBAPE. BR, v. 14, Edição Especial, Rio de Janeiro, Jul. pp. 486-505.
GAIGER, Luiz; ASSEBURG, Benno.

(2007). A economia solidária diante das desigualdades. Dados [online]. Revista de Ciências Sociais, vol. 50, n. 3, pp. 499-533. Disponivel em: http://www.scielo.br/ scielo.php?pid=S0011-52582007000300003\& script=sci_abstract\&tlng=es

GAIGER, Luiz.

(2008). A economia solidária e o valor das relações sociais vinculantes. Ver. Katál. Florianópolis, v.11, n.1, p. 11-19, Jan/Jun. Disponível em: https://periodicos.ufsc.br/index.php/katalysis/ article/view/4755/4035

GAIGER, Luiz.

(2000) Sentido e possibilidades da economia solidária hoje. In: KRAYCHETE, G. (Org.) Economia dos setores populares: entre a realidade e a utopia. Salvador: Vozes, 2000.

(2009). Antecedentes e expressões atuais da economia solidária. Revista Crítica de Ciências Sociais, [Online], n. 84. Disponível em: http://journals.openedition.org/rccs/401; D0I: $10.4000 /$ rccs. 401

(2015). A economia solidária na contramarcha da pobreza. Sociologia, Problemas e Práticas, n. 79, pp. 43-63.

(2003). A economia solidária diante do modo de produção capitalista. Caderno CRH, Salvador, n. 39, pp. 181-211, jul./dez. Disponível em: https://portalseer.ufba.br/index.php/crh/articl e/view/18642/12016

(2008). A economia solidária e o valor das relações sociais vinculantes. Rev. katálysis [online]. vol.11, n.1, pp.11-19. Disponível em: http://www.scielo.br/scielo.php?pid=\$141449802008000100002\&script=sci_abstract\&tlng $=\mathrm{pt}$

(2009). Antecedentes e expressões atuais da economia solidária. Revista Crítica de Ciências Sociais [Online]. 84. março. pp. 81-99, colocado online no dia $1^{\circ}$ dez. 2012. Disponível em: http://journals.openedition.org/rccs/401 
(2015). A Economia Solidária na Contramarcha da Pobreza. Revista Sociologia, Problemas e Práticas, n. 79, pp. 43-63. Disponível em: http://www.scielo.mec.pt/scielo.php?script= sci_abstract\&pid=S087365292015000300003\&lng=pt\&nrm=i

\section{LECHAT, N.M.P.}

(2004). Trajetórias intelectuais e o campo da economia solidária no Brasil. Campinas, SP. Tese de Doutorado. Universidade Estadual de Campinas, 388p.

\section{LOCKS, P.}

(2014). Formulação de agenda, Políticas Públicas e Economia Solidária no Brasil. Otra Economía, vol. 8, n. 14, pp. 45-59, enero-junio pp. 45-59.

\section{OLIVEIRA, P. S.}

(2008). Entrevista com Paul Singer. Estudos avançados. vol.22, n. 62. São Paulo. Jan./Apr. Disponivel em:

http://www.scielo.br/scielo.php?script=sci_artt ext\&pid=S0103-40142008000100020

SANTOS, A. M.

(2018). Paul Singer: democracia, economia e autogestão. Marília: Lutas Anticapital.

SINGER, Paul; SOUZA, André Ricardo de (0rgs.). (2000). A economia solidária no Brasil: a autogestão como resposta ao desemprego. São Paulo: Contexto.

SINGER, P.

(1998). Uma utopia militante: repensando o socialismo. São Paulo, Vozes.
(2001). Economia solidária versus economia capitalista. Sociedade e Estado. vol.16 n.1-2. Brasília June/Dec. Acesso em: 04 jan. 2019. Disponível em: http://www.scielo.br/pdf/se/v16n1-2/v16n12a05.pdf

(2002). A recente ressurreição da economia solidária no Brasil. In: SANTOS, Boaventura de Sousa (Org.) Produzir para viver: os caminhos da produção não capitalista. Rio de Janeiro: Civilização Brasileira.

SINGER, P. et al.

(2003). A Economia Solidária no Brasil: a autogestão como resposta ao desemprego. 2. ed. São Paulo: Contexto.

SOUZA. A. R.

(2018). Professor Paul Singer e a Economia Solidária. P2P \& Inovação, Rio de Janeiro, v. 5 n. 1, Ed. Especial, pp.43-52.

\section{Recebido em}

novembro de 2019

\section{Aprovado em}

abril de 2020 